\title{
Prospective clinical evaluation of 765 partial glass-ceramic posterior restorations luted using photo-polymerized resin composite in conjunction with immediate dentin sealing
}

\author{
Carline R. G Van den Breemer ${ }^{1} \cdot$ Gerrit J. Buijs ${ }^{2} \cdot$ Marco S. Cune $^{1,3,4} \cdot$ Mutlu Özcan $^{5} \cdot$ Wouter Kerdijk $^{6} \cdot$ Stephan Van \\ der Made ${ }^{7}$ - Marco M. M. Gresnigt ${ }^{1,8}$
}

Received: 18 July 2018 / Accepted: 7 July 2020 / Published online: 12 August 2020

(C) The Author(s) 2020

\begin{abstract}
Objectives To evaluate the clinical performance of partial glass-ceramic (IPS e.max Press) posterior restorations.

Materials and methods A total of 765 restorations in 158 patients were placed between 2008 and 2018 and evaluated in a prospective study during regular dental care visits between 2015 and 2018. The restorations were luted with a conventional photo-polymerized resin composite (HFO) in conjunction with an Immediate Dentin Sealing procedure (IDS). Intra-oral photographs and radiographs were made and evaluated using USPHS criteria.

Results The mean observation time was 53.3 months (range 3-113 months). Three absolute failures occurred (tooth fractures, $n=2$; apical re-infection, $n=1$ ) all leading to the loss of the restored tooth. Repairable and salvageable failures occurred in 9 teeth (endodontic complications, $n=7$; secondary caries, $n=1$; debonding, $n=1$ ). The survival and success rates according to KaplanMeier after 5 years cumulated to $99.6 \%$ and $98.6 \%$, respectively. Location (premolar/molar and mandibula/maxilla), prerestorative endodontic status (vital/devitalised) and extension of the indirect ceramic restoration (number of sides and cusps involved) did not significantly affect the cumulative success rate (log rank test, $p>0.05$ ). The condition of the vast majority of the restorations remained unaffected for 5 years.

Conclusions Partial glass-ceramic posterior restorations (pressed lithium disilicate (IPS e.max press, Ivoclar Vivadent) luted by means of a conventional photo-polymerized resin composite in conjunction with the use of an IDS procedure have an excellent medium-term prognosis.

Clinical relevance Partial glass-ceramic posterior restorations can be considered as a highly reliable treatment option. Location and extension of the restoration and pre-restorative endodontic status do not affect success rate.
\end{abstract}

Keywords Adhesion · Posterior $\cdot$ Immediate dentin sealing $\cdot$ Partial restorations $\cdot$ Lithium disilicate $\cdot$ Survival

\section{Introduction}

Partial indirect restorations can be indicated when it is difficult to restore form and function using direct composite

Carline R. G Van den Breemer

c.r.g.van.den.breemer@umcg.nl

1 Department of Restorative Dentistry and Biomaterials, Center for Dentistry and Oral Hygiene, University Medical Center Groningen, Antonius Deusinglaan 1, 9713, AV Groningen, The Netherlands

2 Groningen, The Netherlands

3 Department of Oral-Maxillofacial Surgery, Prosthodontics and Special Dental Care, St. Antonius Hospital Nieuwegein, Nieuwegein, The Netherlands restorations. Monolithic reinforced glass-ceramic restorations have gained popularity in posterior teeth as these restorations are less prone to fracture compared to feldspathic ceramic [1]. Lithium disilicate restorations have an increased fracture

4 Department of Oral Maxillofacial Surgery, Prosthodontics and Special Dental Care, University Medical Center Utrecht, Utrecht, The Netherlands

5 Division of Dental Materials, Center for Dental and Oral Medicine, Clinic for Fixed and Removable Prosthodontics and Dental Materials Science, University of Zurich, Zurich, Switzerland

6 Department of Education and Research, Hanze University of Applied Sciences, Groningen, The Netherlands

7 Kwalident Dental Studio, Beilen, The Netherlands

8 Department of Special Care, Martini Hospital, Groningen, The Netherlands 
toughness from the crystallites as these induce the fracture to bow, deflect and branch [2]. Besides their strength, adhesive luting is possible and this increases strength and regain aesthetics at a minimum biological price, removing defect structures only [3-5].

A recent systematic literature review revealed a cumulative survival rate for single glass-ceramics and feldspathic porcelain restorations of $92-95 \%$ after 5 years, and $91 \%$ after 10 years [6]. Due to high load in the posterior region, these restorations were more prone to fracture than crowns in the anterior region $[7,8]$. In shortterm evaluations, bulk fracture, chipping of the ceramic and adhesive problems have been reported as the main reason of failure [9]. Besides restoration failures, secondary caries was observed as a biological complication (1\%) [6]. Comparing acid-etched e.max lithium disilicate monolithic and bilayered complete coverage restorations resulted in an estimated cumulative survival rate of $96.5 \%$ after 10.4 years for monolithic and $100 \%$ after 7.9 years for bilayered restorations. This difference was statistically significant [10]. Long-term data with a high number of these partial all-ceramic restorations is unfortunately limited, which precludes firm statements regarding their effectiveness [11].

Adhesive bonding to dentin has been considered as the weakest link in clinical durability and fracture resistance of ceramic restorations [12]. The so-called immediate dentin sealing concept (IDS) has been studied extensively in in vitro studies and obtained significantly increased bond strengths [13-21]. An vitro study demonstrated that the application of an IDS layer with ceramic inlays significantly increased fracture strengths [22].

The use of a conventional photo-polymerized resin composite as a luting agent is debated [23, 24]. Manufacturers and studies claimed that the use of composite as a luting agent with thick or extensive restorations could lead to a decrease in degree of conversion [25-29]. However, luting with composite has some practical advantages, i.e., increased working time, improved biomechanical properties, wear resistance and ease of removal the excess $[25-27,30]$. In addition, recent articles have proved their ability to have a higher bond strength in in vitro $[26,31]$ and in in vivo research $[27,30,32]$.

The aim of this study is to evaluate the clinical survival and success rate of partial glass-ceramic posterior restorations luted with conventional photo-polymerized resin composite in conjunction with the use of IDS. Further evaluation will involve the location of the restoration (premolar/molar and mandibula/maxilla), pre-restorative endodontic status (vital/devitalised) and the extension of the indirect ceramic restoration (number of sides and cusps involved).

\section{Materials and methods}

\section{Study design and inclusion}

All patients, who received posterior partial lithium disilicate ceramic restorations between 2008 up to 2018, were eligible for inclusion for this prospective study. Patients were treated by one operator in a private practice, and all restorations were luted with a conventional photo-polymerized resin composite in conjunction with an IDS. Indirect restorations were provided for various reasons: secondary caries, replacement of a failing direct restoration or fracture of one of the cusps. To be eligible, patients should not have active periodontal or pulpal diseases. This study was evaluated by the medical ethical board of the University Medical Center Groningen and registered in the clinical trial register (NCT3452358). The product, manufacturers and chemical compositions of the materials that were used in this study are listed in Table 1.

\section{Tooth preparation}

All procedures were performed using high magnification $\times 8$ 25 (OpmiPico, Zeiss, Jena, Germany). After isolation using a rubberdam (Hygenic Dental Dam, Coltène Whaledent Inc., Ohio, USA and Nic tone, MDC Dental, Zapopan, Jalisco, Mexico), the existing restorative material was removed. Minimal invasive preparations were made, and sound enamel was not removed. Outlines consisted of a shoulder or chamfer made with a red handpiece and diamond burs (type: $881 \mathrm{G}$ 012, 014 and 016; 880G 023, 881F 012, 8881314 014, 016 (Meisinger, Neuss, Germany)) or with a SONICflex prep ceram handpiece (KaVo, Biberach/Riß, Germany). All internal angles or undercuts were not smoothened but covered using IDS with flowable composite. Regardless of the endodontic status, the cusps were only covered if they were already part of the old restoration or when a fracture line was visible in $>50 \%$ of the cusp. The proximal walls were slightly diverging with an angle of $100^{\circ}$ to $120^{\circ}$ between the proximal cavity walls and the prospective proximal inlay surface. Occlusal marginal ridge contacts were not avoided. Occlusal thickness of the restoration after removing the old restorations was at least $0.5 \mathrm{~mm}$ [33-35]. Immediately following preparation, the tooth received IDS (Clearfil SE Bond, Kuraray, Osaka, Japan). The clinical protocol for tooth preparation and IDS is presented in detail in Table 2. To obtain a smooth surface and to compensate for incidental undercuts after preparation, a flowable resin was applied (GrandIO flow, VOCO, Cuxhaven, Germany). Electrosurgery was performed in cases where retraction of the gingiva was needed to obtain a proper and detailed impression. Impressions were made using a hydrocolloid impression material (VanR Heavy bodied, DUX Dental, USA). Temporary restorations were made chair-side using a chemical cured provisional material (Protemp, 3M ESPE, Seefeld, 
Table 1 The products, manufacturers and chemical composition of the material used in this study

\begin{tabular}{|c|c|}
\hline Product & Composition \\
\hline $\begin{array}{l}\text { IPS e.max Press } \\
\text { (Ivoclar Vivadent, Schaan, Liechtenstein) }\end{array}$ & Pressable ceramic \\
\hline HFO - composite enamel plus UD2 & 1,4-Butandioldimethacrylate, urethane \\
\hline (Micerium S.p.A., Avegno, Italy) & dimethacrylate, Bis-GMA \\
\hline $\begin{array}{l}\text { CoJet }{ }^{\circledR} \text {-sand } \\
(3 \mathrm{M} \text { ESPE, Neuss, Germany) }\end{array}$ & Aluminium trioxide particles coated with silica, $30 \mu \mathrm{m}$ \\
\hline $\begin{array}{l}\text { ESPE®-sil } \\
\text { (3M ESPE, Neuss, Germany) }\end{array}$ & Ethyl alcohol, 3-methacryloxy-propyltrimethoxysilane, ethanol \\
\hline $\begin{array}{l}\text { Monobond Plus } \\
\text { (Ivoclar Vivadent, Schaan, Liechtenstein) }\end{array}$ & One component primer \\
\hline $\begin{array}{l}\text { Clearfil SE Bond } \\
\text { (Kuraray, Osaka, Japan) }\end{array}$ & $\begin{array}{l}\text { Primer: HEMA, hydrophilic dimethacrylate, water, photo initiator } \\
\text { Adhesive: TEDGMA, UDMA, GPDM, HEMA, bis-GMA, filler, photo initiator }\end{array}$ \\
\hline $\begin{array}{l}\text { Porcelain etch } \\
\text { (Ultradent, South Jordan, UT, USA) }\end{array}$ & 9\% Hydrofluoric acid \\
\hline $\begin{array}{l}\text { Ultra-etch } \\
\text { (Ultradent, South Jordan, UT, USA) }\end{array}$ & $35 \%$ Phosphoric acid \\
\hline $\begin{array}{l}\text { GrandIO flow } \\
\text { (VOCO, Cuxhaven, Germany) }\end{array}$ & 1,6-Hexanediylbismethacrylate, BIS-GMA, triethylene glycol dimethacrylate \\
\hline $\begin{array}{l}\text { K-Y* lubricating gelly } \\
\text { (Johnson \& Johnson, Sezanne, France) }\end{array}$ & $\begin{array}{l}\text { Purified water, glycerin, methylparaben, propylparaben, propylene glycol, } \\
\text { hydroxyethylcellulose, dissodium, phosphate, sodium phosphate, tetrasodium, EDTA }\end{array}$ \\
\hline $\begin{array}{l}\text { Hygenic Dental dam } \\
\text { (Coltène/Whaledent Inc., Ohio, USA) }\end{array}$ & Rubberdam \\
\hline $\begin{array}{l}\text { Nic tone Dental Dam } \\
\text { (MDC Dental, Zapopan, Jalisco, Mexico) }\end{array}$ & Rubberdam \\
\hline $\begin{array}{l}\text { Durelon } \\
\text { (3M ESPE, Neuss, Germany) }\end{array}$ & Powder: zinc oxide, stannous fluoride, tin dioxide Liquid: water, polyacrylic acid \\
\hline $\begin{array}{l}\text { Brownies } \\
\text { (Shofu, Kyoto, Japan) }\end{array}$ & Polisher, medium \\
\hline $\begin{array}{l}\text { Impression material } \\
\text { (VanR Heavy bodied, DUX Dental, USA) }\end{array}$ & Hydrocolloid impression material \\
\hline
\end{tabular}

Germany). They were temporarily luted using a polycarboxylate cement (Durelon, 3M ESPE Seefeld, Germany).

\section{Luting procedure}

All pressed lithium disilicate restorations (IPS e.max press, Ivoclar Vivadent) were fabricated in a dental laboratory using magnification loups $\times 4.2$ (Examvision, Rotterdam, The Netherlands) and microscope $\times 8-25$ (OpmiPico, Zeiss) following the manufacturer's instructions. Restorations were made by the lost wax technique using pressable ceramics (IPS e.max, Ivoclar Vivadent). To get correct shade integration, a staining technique was used (IPS e.max Stains, Ivoclar Vivadent) and glazed afterwards (IPS e.max Fluoglaze, Ivoclar Vivadent). Hereafter, the restorations were handpolished (Signum HP diamond polishing, Hereaus Kulzer GmbH, Hanau, Germany). The clinical protocol for preparation of tooth and the ceramic restorations are presented in detail in Tables 2 and 3. The temporary restoration was removed, and the teeth were cleansed from temporary cement with an ultrasonic tip or a hand scaler. The IDS layer was silica coated (30 $\mu \mathrm{m} \mathrm{SiO}_{2}$ Cojet-sand, $3 \mathrm{M} \mathrm{ESPE)} \mathrm{using} \mathrm{an} \mathrm{intra-}$ oral air-abrasion device (Dento-prepTM, RØNVIG A/S, Daugaard, Denmark) at a pressure of 2.5 bar from a distance of approximately $10 \mathrm{~mm}$ for $2-3 \mathrm{~s}$. The adjacent teeth were protected using a metal strip during air-abrasion procedure. Try-in of the partial ceramic restoration was done, and margins were checked. Subsequently, the adjacent teeth were protected with teflon tape (PTFE tape) and enamel etched with phosphoric acid (Ultradent, South Jordan, UT, USA). Then, the preparation was rinsed with copious water for $20 \mathrm{~s}$, dried with oil-free compressed air and silane (EPSE-sil, 3M ESPE, Neuss, Germany) applied at the IDS layer and left to react with the silica particles for $1 \mathrm{~min}$.

After etching the restoration with $9 \%$ hydrofluoric acid (Porcelain etch, Ultradent), the restorations were ultrasonically cleaned in distilled water for $5 \mathrm{~min}$. After cleaning, the intaglio surface of the lithium disilicate restoration was silanized (Monobond Plus, Ivoclar Vivadent). The procedure 
Table 2 Clinical protocol for tooth preparation and Immediate Dentin Sealing
First visit: Preparation of the tooth before impression

*Tooth preparation is ready for impression, followed by:

1.1 Apply SE Primer (Clearfil SE Bond, Kuraray), active brushing motion

$20 \mathrm{~s}$

1.2 Air suction

1.3 Apply SE Adhesive (Clearfil SE Bond, Kuraray), active brushing motion $\quad 10 \mathrm{~s}$

1.4 Air-thin

$10 \mathrm{~s}$

$10 \mathrm{~s}$

1.5 Photo-polymerize

$40 \mathrm{~s}$

1.7 Photo-polymerize

1.8 Apply glycerin gel (K-Y* lubricating gelly, Johnson \& Johnson, Sezanne, France)

1.9 Photo-polymerize at buccal, oral and proximal sites

$40 \mathrm{~s}$ each

1.10 Rinse until clean surface

1.11 Clean enamel outline with a rubberpoint or a bur

1.12 Take impression

Second visit: Preparation of the tooth before luting

2.1 Clean tooth surface ultrasonically or with a scaler

2.2 Silica coat the immediate dentin sealing layer (CoJet ${ }^{\circledR}$-sand, 3 M ESPE, Neuss, Germany)

$2-3 \mathrm{~s}$

2.3 Acid etch the enamel (not the accidently exposed dentin)

\section{$30 \mathrm{~s}$}

$30 \mathrm{~s}$

2.5 Dry

2.6 Apply Silane (ESPE - Sil, 3 M ESPE) on the immediate dentin sealing layer

$60 \mathrm{~s}$

$10 \mathrm{~s}$

2.8 Apply composite (HFO composite, Micerium S.p.A., Avegno, Italy) onto the tooth

2.9 Place the partial restoration onto the tooth

2.10 Remove excess of cement

2.11 Photo-polymerize

$40 \mathrm{~s}$

2.12 Apply of glycerin gel (K-Y* lubricating gelly, Johnson \& Johnson)

2.13 Photo-polymerize at buccal, oral and proximal sides

$0 \mathrm{~s}$
$0 \mathrm{~s}$
$0 \mathrm{~s}$
$\mathrm{~s}$

each


(buccal/lingual/palatinal/mesial/distal) and cusps involved) was noted.

\section{Evaluation}

All patients were evaluated at regular intervals (i.e., every 6 months), with special emphasis and attention paid to the partial restoration(s) every time they visited the clinic for regular dental check-ups between 2015 and 2018 .
To assess the condition of the restorations, a light photograph was made with a digital camera (Nikon (D7100, 60-mm lens), Nikon, Amsterdam, The Netherlands) at each follow-up session and subsequently evaluated by an independent researcher according to the modified United States Public Health Service (USPHS) criteria (Table 4, 11 parameters). Intra-oral radiographs were made when indicated. Patient's records were checked for the occurrence of failures. Restorations were not replaced after endodontic treatments but restored by a composite restoration and continued to

Table 4 Criteria used for the clinical evaluations of the restorations (adapted version of modified United States Public Health Service (USPHS) criteria)

\begin{tabular}{|c|c|c|}
\hline Category & Score* & Criteria \\
\hline \multirow[t]{4}{*}{ 1. Photograph — adaptation restoration } & 0 & Restorations contour is continuous with existing anatomical form and margins of the restoration \\
\hline & 1 & Restoration is slightly under of over contoured \\
\hline & 2 & Marginal overhang or tooth structure (dentin or enamel) is exposed \\
\hline & 3 & Restoration is missing, traumatic occlusion or restoration cause pain in tooth or adjacent tissue \\
\hline \multirow[t]{2}{*}{ 2. Photograph—caries } & 0 & No visible caries \\
\hline & 1 & Caries contiguous with the margin of the restoration \\
\hline \multirow[t]{4}{*}{ 3. Photograph - marginal adaptation } & 0 & Excellent continuity at resin — enamel interface; no ledge formation, no discoloration \\
\hline & 1 & Slight discoloration at resin —enamel interface; ledge at interface \\
\hline & 2 & Moderate discoloration at resin —enamel interface measuring $1 \mathrm{~mm}$ or greater \\
\hline & 3 & Recurrent decay at margin \\
\hline \multirow[t]{4}{*}{ 4. Photograph - polishability } & 0 & Smooth and highly shiny, similar to enamel \\
\hline & 1 & Smooth and satin, highly reflective \\
\hline & 2 & Rough and shiny, satin, somewhat reflective \\
\hline & 3 & Rough and dull or satin, not reflective \\
\hline \multirow[t]{2}{*}{ 5. Photograph—surface staining } & 0 & Absent \\
\hline & 1 & Present \\
\hline \multirow[t]{2}{*}{ 6. Photograph—contact points } & 0 & Present \\
\hline & 1 & Absent \\
\hline \multirow[t]{6}{*}{ 7. Photograph - fracture of restoration } & 0 & No fracture of the restoration \\
\hline & 1 & Small lines of the restoration \\
\hline & 2 & Small chippings ( $1 / 4$ of restoration) \\
\hline & 3 & Moderate chippings ( $1 / 2$ of restoration) \\
\hline & 4 & Severe chippings ( $3 / 4$ of restoration) \\
\hline & 5 & Loose of the restoration \\
\hline \multirow[t]{2}{*}{ 8. Photograph—wear restoration } & 0 & No wear \\
\hline & 1 & Wear \\
\hline \multirow[t]{4}{*}{ 9. Radiopgraph — adaptation restoration } & 0 & Restorations contour is continuous with existing anatomical form and margins \\
\hline & 1 & Restoration is slightly under of over contoured \\
\hline & 2 & Marginal overhang or tooth structure (dentin or enamel) is exposed \\
\hline & 3 & Restoration is missing, traumatic occlusion or restoration cause pain in tooth or adjacent tissue \\
\hline \multirow[t]{2}{*}{ 10. Radiopgraph — caries } & 0 & No visible caries \\
\hline & 1 & Caries contiguous with the margin of the restoration \\
\hline \multirow[t]{4}{*}{ 11. Radiopgraph — marginal adaptation } & 0 & Excellent continuity at resin —enamel interface; no ledge formation, no discoloration \\
\hline & 1 & Slight discoloration at resin — enamel interface; ledge at interface \\
\hline & 2 & Moderate discoloration at resin —enamel interface measuring $1 \mathrm{~mm}$ or greater \\
\hline & 3 & Recurrent decay at margin \\
\hline
\end{tabular}

*Scores 0, 1, 2, 3, 4 and 5 can also be read as Alpha, Beta, Charlie, Delta, Echo and Foxtrot 
follow-up. The findings were to be compared with those obtained at baseline and to all other follow-up events.

The data for all 11 USPHS parameters were presented at yearly intervals, with observation periods stretching from 'baseline' to ' 5 years and longer'. The observations were attributed to the closest full year.

\section{Statistical analysis}

For an estimation of the cumulative success and survival rate in relation to observation time, the Kaplan-Meier method was used. Subgroup analysis for the cumulative survival and success rate was performed for location (mandibula/maxilla), prerestorative endodontic status (vital/devitalised) and the extension of the indirect ceramic restoration (number of surfaces and cusps involved) using the log rank test.

Only restorations with ratings of 0 in the USPHS criteria were considered a 'success'; hence, for the success rate, 'an event' was defined when a USPHS-score larger than 0 was observed on any of the 11 evaluated qualitative aspects. For the calculation of the chance on survival, 'an event' was noted when the restoration or the tooth itself was no longer salvageable.

The USPHS scores for the various domains are tabulated across 6 observation periods using descriptive statistics. A USPHS sum score is calculated as a general indication for the quality of the restoration, by adding the scores for the various domains. Mean values and standard deviations are calculated and compared in time using non parametric statistics (Kruskal-Wallis test and post hoc Mann-Whitney $U$ tests, after Bonferroni correction $p$ values $<0.0033$ were considered statistically significant.

Statistical analyses were performed with a statistical software program (SPSS 22.0; SPSS Inc., Chicago, IL, USA).

\section{Results}

In total, 765 partial restorations in 158 patients $(60$ men, 98 women) could be included: of which 697 restorations on vital teeth and 68 on devitalised teeth. In total, 360 restorations were placed in the mandibula and 405 in the maxillary posterior teeth, 282 on premolars and 483 on molars. The mean observation time was 53.3 months (range 3-113 months).

In three cases, the extension of the indirect ceramic restoration could not be determined from the photograph made at baseline, nor from the patients' record. The number of sides (buccal/lingual/palatinal/mesial/distal) that the restorations replaced were as follows: 2 sides: 12, 3 sides: 198, 4 sides: 262 and 5 sides: 290 . The number of cusps that were replaced by the restoration were as follows: 0 cusp $n=409,1$ cusp $n=$ 179, 2 cusp $n=110,3$ cusps $n=19$ and 4 cusps $n=45$.
The overall estimated cumulative survival rate according to Kaplan-Meier after 5 years of function and longer is $99.6 \%$ (SE 0.3\%, 3 events) and the success rate are 98.6\% (SE 0.5\%, 9 events) after 5 years and $96 \%$ (SE 1.7\%) after 7.5 years and longer (12 events, Figs. 1 and 2). Three cases were absolute failures and thus extracted, 2 being a fracture of a tooth after 10 months (devitalised) and a tooth after 33 months (vital) with restorations without cusp coverage. A non-salvageable apical re-infection occurred in another tooth after 18 months of function.

Over time, repairable and salvageable failures occurred in 9 teeth, being endodontic treatment needed $(n=7)$, secondary caries $(n=1)$ and debonding of the restoration $(n=1)$. Location (premolar/ molar and mandibular/maxilla), extension of the indirect ceramic restoration (number of sides and cusps involved) and pre-restorative endodontic treatment (vital/devitalised) did not significantly affect the cumulative success rate (log rank test, $p>0.05$ ).

The USPHS data across the different observation periods are presented in Table 5 by means of frequency distributions. The condition of the vast majority of the restorations was excellent and remained unaffected after 5 years of function or longer, as also represented by the USPHS sum score. A Kruskal-Wallis test was performed to explore the USPHS sum scores in time, i.e. baseline to $>5$ years. There is a statistically significant difference between the USPHS sum scores in time $(p<0.001)$. The results of the post-hoc tests after Bonferroni correction show a significant difference between the USPHS sum score at baseline and the scores for the subsequent time intervals $(1,2,3,4$ and $>5$ years). Hence, some deterioration of the general quality of the restoration is seen after the first year of clinical service, but it remained stable thereafter (Table 5).

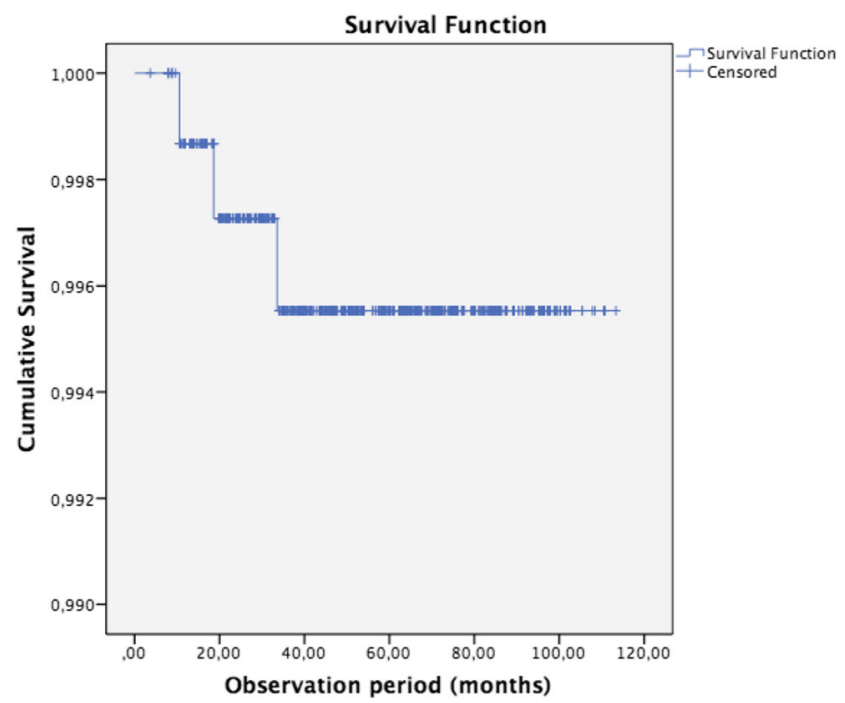

Fig. 1 Kaplan-Meier curve of the cumulative survival rate after 5 years and longer is $99.6 \%$ SE $0.3 \%$ ( $n=765$ at baseline, events $n=3)$ 


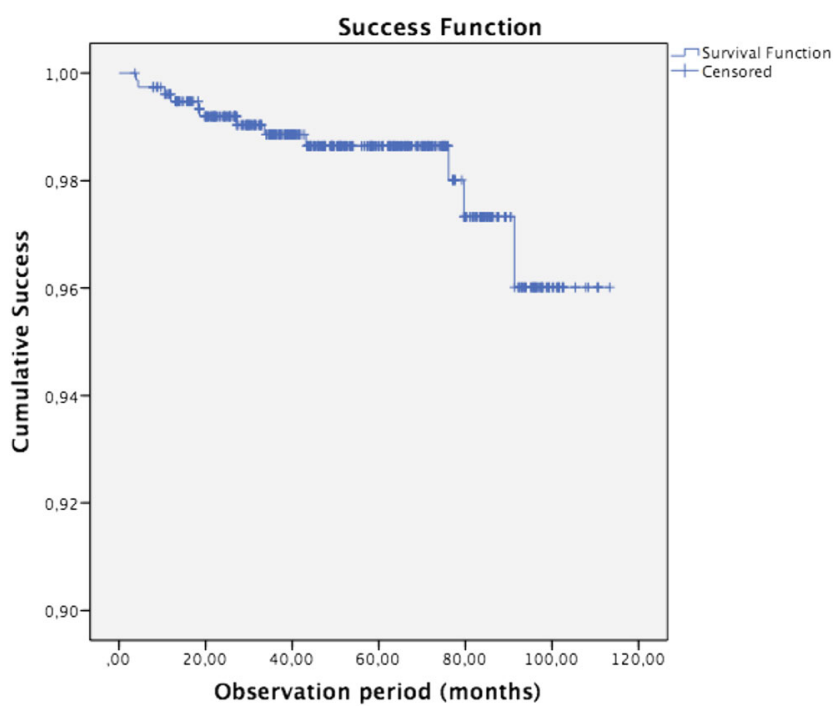

Fig. 2 Kaplan-Meier curve of the cumulative success rate after 5 years is $98.6 \%$ SE $0.5 \%$ and $96.0 \%$ SE $1.7 \%$ after 7.5 years and longer $(n=765$ at baseline, events $n=12$ )

\section{Discussion}

In this prospective study, the clinical performance of 765 partial glass-ceramic posterior restorations luted by means of a conventional photo-polymerized resin composite in conjunction with Immediate Dentin Sealing were evaluated. Restorations presented excellent estimated cumulative survival and success rates after 5 years, being $99.6 \%$ and $98.6 \%$, respectively. A representative case is presented in Fig. 3. No clinical study has been performed on partial ceramic restorations using Immediate Dentin Sealing and a conventional photo-polymerized resin composite.

The results of this study are better than other studies on allceramic partial restorations not using IDS and composite with short (2 years; $100 \%$ [32]) to medium-term (5-8 years; $94.8-$ 97.4\% [5], 7 years; 97\%-100\% [36],4 years; 93\%-100\% [37-39]) observation periods. The evidence for such restorations with longer follow-up time and high numbers of patients is limited [22].

One review reported an estimated survival rate of $95 \%$ after 5 years and $93 \%$ after 10 years [6], and compared to the survival of conventional posterior full crowns (metal-ceramic $(94.7 \%)$ and lithium disilicate reinforced glass-ceramic (96.6\%) after 5 years) [40], the partial restorations in this study show a higher survival rate. One of the possibilities for the excellent outcome of this study is the use of a conventional photo-polymerized resin composite as the luting agent [41]. A dual-polymerized composite resin to lute ceramic inlays was used in the vast majority of other clinical studies $[5,6,37,38$, $42,43]$. Previous studies which investigated the use of photopolymerized composite resins for luting purposes produced conflicting results $[28,29]$. Presumed reduced wear of luting composites could not be confirmed when using the higher filled luting material [28]. However, more recent studies on this subject are promising [25-27, 31]. The higher filler content and lower initiator concentration compared to dualpolymerized resin cements may be beneficial in terms of mechanical strength and the wear properties at the exposed margins [29]. Even thick restorations are not contra-indicated with photo-polymerized luting composites in combination with IDS [25] but the use of a high power photo-polymerized (> $2000 \mathrm{~mW} / \mathrm{cm}^{2}$ ) unit and extended polymerization time are considered of critical importance [26]. A decrease in marginal adaptation of ceramic restorations over time is reported in the current literature, as marginal deterioration can be attributed to degradation and wear of the composite [12, 44]. An important factor for the clinical long-term performance of partial coverage restorations is marginal degradation on the resin cement and deterioration of the all-ceramic materials during clinical function [45]. Based on the results of this study, the USPHS criteria according marginal adaptation showed very good results over time even with restorations up to 5 year or more because of the favourable properties of the conventional photo-polymerized resin composite.

Two absolute failures occurred due to fracture in the root of the teeth. One of these catastrophic fractures was in a vital teeth and one in a devitalised teeth. Both of these fractures occurred in teeth without cusp coverage. Several authors suggest cusp coverage to restore weak posterior teeth [46, 47]. However, the amount of 0 and 1 cusp-replaced restorations were high in this study. Almost no cusp coverage was performed due to removal of sound tissue as little as possible. The results of this study showed that the extension of the restoration and the pre-restorative endodontic status did not challenge the survival. Probably due to the adhesive quality with the use of IDS and conventional photo-polymerized resin composite, cusp coverage is no longer required. But further research is necessary to confirm this statement.

Fractures of the ceramic material or minor chipping in general were not observed, which may be contributed to meticulous polishing of the ceramic material when small occlusal corrections were deemed necessary after luting. This may have prevented micro cracks that could lead to catastrophic failures in due time [30]. An additional risk for crack formation is polymerization shrinkage of the luting composite, which creates stress concentrations at the adhesive interface and at the ceramic subsurface [48]. When using IDS with indirect bonded restorations, the delayed placement of the restorations and postponed occlusal loading facilitate the dentin bond to develop without stress [49]. The use of IDS may have led to less fractures and chippings in this study. However, the use of a lithium disilicate is also known to have higher mechanical properties that produces less fractures compared to other ceramics like leucite reinforced glass-ceramic and feldspathic glass-ceramics [1]. 
Table 5 Frequency distributions (\%) of the scores on the 11 USPHS criteria and USPHS sum score (mean \pm SD), clustered by period in time

\begin{tabular}{|c|c|c|c|c|c|c|c|}
\hline Photograph & & Baseline & 1 year & 2 years & 3 years & 4 years & $>5$ years \\
\hline & & $(n=765)$ & $(n=192)$ & $(n=166)$ & $(n=156)$ & $(n=122)$ & $(n=197)$ \\
\hline \multirow[t]{5}{*}{ 1. Adaptation restoration $(\min =0, \max =3)$} & $0 *$ & $100 \%$ & $99.5 \%$ & $99.4 \%$ & $100 \%$ & $99.2 \%$ & $100 \%$ \\
\hline & 1 & & $0.06 \%$ & $0.8 \%$ & & & \\
\hline & 2 & & & & & & \\
\hline & 3 & & & & & & \\
\hline & & $(n=765)$ & $(n=192)$ & $(n=166)$ & $(n=156)$ & $(n=122)$ & $(n=197)$ \\
\hline \multirow[t]{3}{*}{ 2. Caries $(\min =0, \max =1)$} & 0 & $100 \%$ & $99 \%$ & $99.4 \%$ & $99.4 \%$ & $100 \%$ & $99.5 \%$ \\
\hline & 1 & & $1 \%$ & $0.6 \%$ & $0.6 \%$ & & $0.5 \%$ \\
\hline & & $(n=765)$ & $(n=192)$ & $(n=166)$ & $(n=156)$ & $(n=122)$ & $(n=197)$ \\
\hline \multirow[t]{5}{*}{ 3. Marginal adaptation $(\min =0, \max =3)$} & 0 & $100 \%$ & $97.4 \%$ & $97 \%$ & $94.2 \%$ & $96.7 \%$ & $82.2 \%$ \\
\hline & 1 & & $2.6 \%$ & $1.8 \%$ & $5.8 \%$ & $3.3 \%$ & $17.3 \%$ \\
\hline & 2 & & & $1.2 \%$ & & & $0.5 \%$ \\
\hline & 3 & & & & & & \\
\hline & & $(n=765)$ & $(n=192)$ & $(n=166)$ & $(n=156)$ & $(n=122)$ & $(n=197)$ \\
\hline \multirow[t]{5}{*}{ 4. Polishability $(\min =0, \max =3)$} & 0 & $100 \%$ & $99 \%$ & $97.6 \%$ & $100 \%$ & $100 \%$ & $98.5 \%$ \\
\hline & 1 & & $1 \%$ & $2.4 \%$ & & & $1.5 \%$ \\
\hline & 2 & & & & & & \\
\hline & 3 & & & & & & \\
\hline & & $(n=765)$ & $(n=192)$ & $(n=166)$ & $(n=156)$ & $(n=122)$ & $(n=197)$ \\
\hline \multirow[t]{3}{*}{ 5. Surface staining $(\min =0, \max =1)$} & 0 & $100 \%$ & $99 \%$ & $99.4 \%$ & $98.7 \%$ & $99.2 \%$ & $100 \%$ \\
\hline & 1 & & $1 \%$ & $0.6 \%$ & $1.3 \%$ & $0.8 \%$ & \\
\hline & & $(n=765)$ & $(n=192)$ & $(n=166)$ & $(n=156)$ & $(n=122)$ & $(n=196)$ \\
\hline \multirow[t]{3}{*}{ 6. Contact point $(\min =0, \max =1)$} & 0 & $100 \%$ & $99.5 \%$ & $96.4 \%$ & $98.1 \%$ & $97.5 \%$ & $99.5 \%$ \\
\hline & 1 & & $0.5 \%$ & $3.6 \%$ & $1.9 \%$ & $2.5 \%$ & $0.5 \%$ \\
\hline & & $(n=765)$ & $(n=192)$ & $(n=166)$ & $(n=156)$ & $(n=122)$ & $(n=197)$ \\
\hline \multirow[t]{7}{*}{ 7. Fracture of restoration $(\min =0, \max =5)$} & 0 & $100 \%$ & $100 \%$ & $100 \%$ & $100 \%$ & $100 \%$ & $100 \%$ \\
\hline & 1 & & & & & & \\
\hline & 2 & & & & & & \\
\hline & 3 & & & & & & \\
\hline & 4 & & & & & & \\
\hline & 5 & & & & & & \\
\hline & & $(n=765)$ & $(n=192)$ & $(n=166)$ & $(n=156)$ & $(n=122)$ & $(n=197)$ \\
\hline \multirow[t]{2}{*}{ 8. Wear restoration $(\min =0, \max =1)$} & 0 & $100 \%$ & $98.4 \%$ & $99.4 \%$ & $99.4 \%$ & $100 \%$ & $100 \%$ \\
\hline & 1 & & $1.6 \%$ & $0.6 \%$ & $0.6 \%$ & & \\
\hline \multicolumn{8}{|l|}{ Radiograph } \\
\hline & & $(n=765)$ & $(n=128)$ & $(n=111)$ & $(n=100)$ & $(n=109)$ & $(n=164)$ \\
\hline \multirow[t]{5}{*}{ 9. Adaptation restoration $(\min =0, \max =3)$} & 0 & $100 \%$ & $96.9 \%$ & $100 \%$ & $97 \%$ & $99.1 \%$ & $98.2 \%$ \\
\hline & 1 & & $3.1 \%$ & & $3 \%$ & $0.9 \%$ & $1.8 \%$ \\
\hline & 2 & & & & & & \\
\hline & 3 & & & & & & \\
\hline & & $(n=765)$ & $(n=128)$ & $(n=111)$ & $(n=100)$ & $(n=109)$ & $(n=167)$ \\
\hline \multirow[t]{3}{*}{ 10. Caries $(\min =0, \max =1)$} & 0 & $100 \%$ & $100 \%$ & $100 \%$ & $100 \%$ & $100 \%$ & $100 \%$ \\
\hline & 1 & & & & & & \\
\hline & & $(n=765)$ & $(n=128)$ & $(n=111)$ & $(n=100)$ & $(n=109)$ & $(n=167)$ \\
\hline \multirow[t]{4}{*}{ 11. Marginal adaptation $(\min =0, \max =3)$} & 0 & $100 \%$ & $95.3 \%$ & $98.2 \%$ & $99 \%$ & $98.2 \%$ & $99.4 \%$ \\
\hline & 1 & & $4.7 \%$ & $1.8 \%$ & $1 \%$ & $0.9 \%$ & $0.6 \%$ \\
\hline & 2 & & & & & $0.9 \%$ & \\
\hline & 3 & & & & & & \\
\hline USPHS sum score $($ mean $\pm \mathrm{SD}) * *$ & & 0 & $1.2 \pm 0.1$ & $1.0 \pm 0.0$ & $1.0 \pm 0.0$ & $1.1 \pm 0.0$ & $1.2 \pm 0.1$ \\
\hline
\end{tabular}

*Scores 0, 1, 2 and 3 can also be read as Alpha, Bravo, Charlie and Delta

$* * p<0.001$, post-hoc tests indicate baseline $<1$ year $=2$ years $=3$ years $=4$ years $=>5$ years 


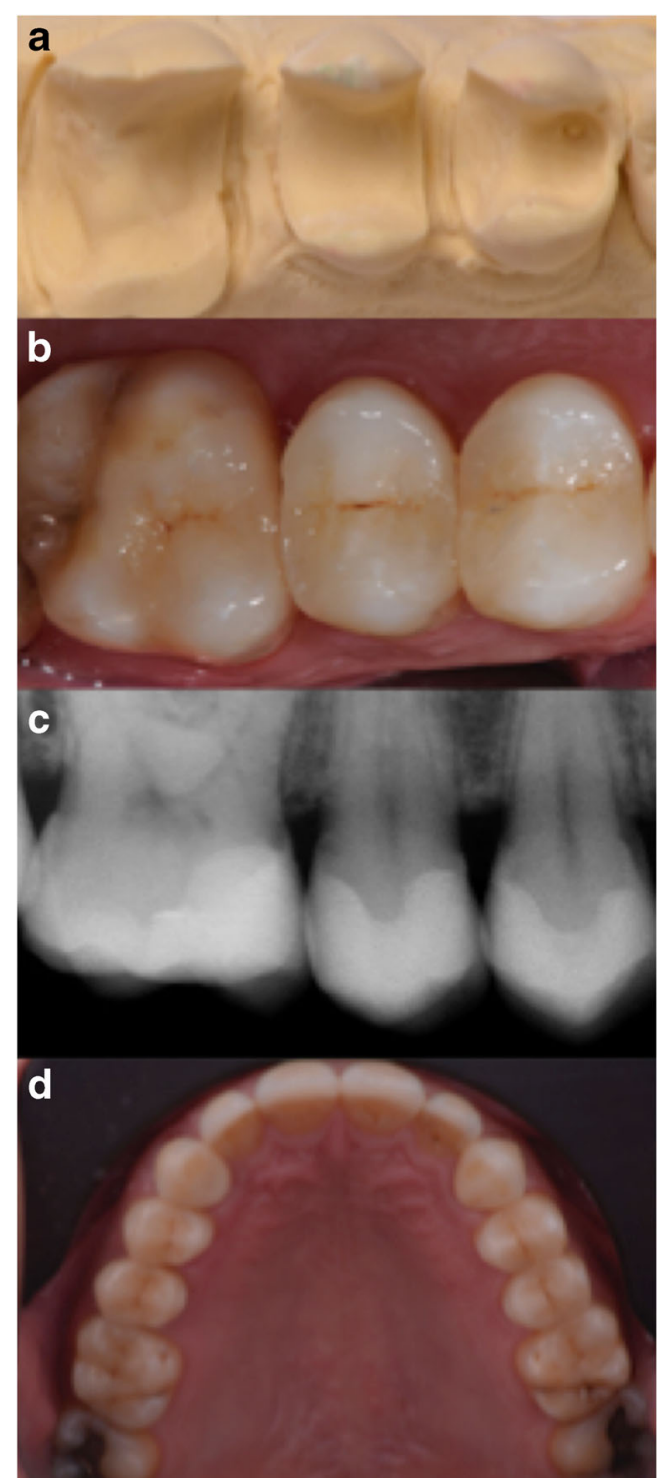

Fig. 3 a-d Representative case restoring teeth 14,15 and 16 . a Preparation design (different case as in $\mathbf{b}, \mathbf{c}, \mathbf{d}$ ). b Photograph directly after placement in 2009. c Radiograph directly after placement in 2009. d Photograph after evaluation in 2016. Total follow-up period being 102 months

Chippings are reported to occur mainly at the marginal area of a restoration, involving small or severe material loss and leaving an irregular oblique fracture plane [50]. Because the condition of the restorations is difficult to assess (fracture lines and small chippings), impression taking for replicas with SEM recordings could provide additional information.

Most frequently observed failures were teeth needing endodontic treatment $(1 \%, n=7)$. The condition of the restorations involved with this complication was still good, with no secondary caries or defects of the restoration. From other studies, it has been reported that failures followed by endodontic complications are seen in 3\% of the cases with ceramic and resin inlays, onlays and overlays [6] and in $15.6 \%$ of the cases with metal-ceramic crowns [51]. The low incidence in the presence study may be the result of the minimal invasive preparation design and the use of IDS. While a circumferential full-crown preparation is associated with the sacrifice of 67.5 to $75.6 \%$ of the original tooth structure, partial preparation is associated with substantially less sacrifice of healthy tooth tissue (5.5 to $27.2 \%$ ) [52]. More invasive, circumferential crown preparations and the use of air turbines are correlated with an increase in pulpal complications [52, 53]. Exposed vital dentin immediately after tooth preparation is susceptible to insult from bacterial infiltration and micro-leakage during the provisionalization phase [13]. Bacterial and fluid penetration through the exposed dentinal tubules can result in colonization of micro-organisms, post-operative sensitivity and the potential for subsequent irritation of the pulp [13]. The use of Immediate Dentin Sealing is postulated to avoid these possible sequelae $[13,54]$, thereby playing an important role in keeping tooth vitality and possibly preventing teeth from hypersensitivity.

One experienced operator performed all operative procedures which increases internal, but decreases external, validity of the observations and stresses the importance of meticulous description of the operative procedures used. The difference between operators (for example seating pressure, operating time and experience) on clinical outcome is well recognized $[26,55]$. However, in this study, a conventional photopolymerized resin composite is used as a luting agent and this technique may be less technique-sensitive and therefore less prone to application errors. It is also easier to remove composite excess when a various direct composite resin rather than a low viscous material is used [26]. The use of highquality intra-oral photographs mainly had a practical reason, so the clinical performance could be judged and critically appraised by one and the same observer, not being the treating physician, outside office times. This procedure may even be preferred over clinical evaluation when judging dental restorations [56].

The present investigation is a prospective clinical study; several clinical variables (restoration size and intra-oral distribution) could act as cofounders. Considering these limitations, further in vivo investigations would be necessary to validate the clinical performance and efficacy of lithium disilicate partial restorations, given different cementation procedures confirming the effectiveness of the approach used in this study.

\section{Conclusions}

Under the given circumstances and conditions as presented in this prospective study, partial glass-ceramic posterior restorations luted with a conventional photopolymerized resin composite in conjunction with the use 
of Immediate Dentin Sealing have an excellent mediumterm prognosis.

Funding information The work was supported by the Department of Fixed and Removable Prosthodontics and Biomaterials, University of Groningen, University Medical Center Groningen, Center for Dentistry and Oral Hygiene, Groningen, The Netherlands. Restorations were made in a private practice where patients paid for their treatments.

\section{Compliance with ethical standards}

Conflict of interest The authors they have no conflict of interest.

Ethical approval All procedures performed in studies involving human participants were in accordance with the ethical standards of the institutional and/or national research committee and with the 1964 Helsinki Declaration and its later amendments or comparable ethical standards.

Informed consent For this type of study, formal consent is not required.

Open Access This article is licensed under a Creative Commons Attribution 4.0 International License, which permits use, sharing, adaptation, distribution and reproduction in any medium or format, as long as you give appropriate credit to the original author(s) and the source, provide a link to the Creative Commons licence, and indicate if changes were made. The images or other third party material in this article are included in the article's Creative Commons licence, unless indicated otherwise in a credit line to the material. If material is not included in the article's Creative Commons licence and your intended use is not permitted by statutory regulation or exceeds the permitted use, you will need to obtain permission directly from the copyright holder. To view a copy of this licence, visit http://creativecommons.org/licenses/by/4.0/.

\section{References}

1. Zhang Z, Yi Y, Wang X, Guo J, Li D, He L, Zhang S (2017) A comparative study of progressive wear of four dental monolithic, veneered glass-ceramics. J Mech Behav Biomed Mater 74:111-117

2. Lohbauer U, Muller FA, Petschelt A (2008) Influence of surface roughness on mechanical strength of resin composite versus glass ceramic materials. Dent Mater 24:250-256

3. Etman MK, Woolford MJ (2010) Three-year clinical evaluation of two ceramic crown systems: a preliminary study. J Prosthet Dent 103:80-90

4. Dietschi D, Spreafico R (1997) Adhesive metal-free restorations. Current concepts for the Esthetic Treatment of Posterior Teeth. Quintessence Books

5. Gehrt M, Wolfart S, Rafai N, Reich S, Edelhoff D (2013) Clinical results of lithium-disilicate crowns after up to 9 years of service. Clin Oral Investig 17:275-284

6. Morimoto S, Rebello de Sampaio FB, Braga MM, Sesma N, Ozcan M (2016) Survival rate of resin and ceramic inlays, onlays, and overlays: a systematic review and meta-analysis. J Dent Res 95: 985-994

7. Pjetursson BE, Sailer I, Zwahlen M, Hammerle CH (2007) A systematic review of the survival and complication rates of all-ceramic and metal-ceramic reconstructions after an observation period of at least 3 years. Part I: Single crowns Clin Oral Implants Res 18(Suppl 3): $73-85$
8. Wang X, Fan D, Swain MV, Zhao K (2012) A systematic review of all-ceramic crowns: clinical fracture rates in relation to restored tooth type. Int J Prosthodont 25:441-450

9. Manhart J, Chen H, Hamm G, Hickel R (2004) Buonocore memorial lecture. Review of the clinical survival of direct and indirect restorations in posterior teeth of the permanent dentition. Oper Dent 29:481-508

10. Malament KA, Natto ZS, Thompson V, Rekow D, Eckert S, Weber HP (2019) Ten-year survival of pressed, acid-etched e.max lithium disilicate monolithic and bilayered complete-coverage restorations: performance and outcomes as a function of tooth position and age. J Prosthet Dent 121:782-790

11. Hayashi M, Yeung CA (2004) Ceramic inlays for restoring posterior teeth. Aust Dent J 49:60

12. van Dijken JW, Hasselrot L, Ormin A, Olofsson AL (2001) Restorations with extensive dentin/enamel-bonded ceramic coverage. A 5-year follow-up. Eur J Oral Sci 109:222-229

13. Qanungo A, Aras MA, Chitre V, Mysore A, Amin B, Daswani SR (2016) Immediate dentin sealing for indirect bonded restorations. J Prosthodont Res

14. Dalby R, Ellakwa A, Millar B, Martin FE (2012) Influence of immediate dentin sealing on the shear bond strength of pressed ceramic luted to dentin with self-etch resin cement. Int J Dent 2012: 310702

15. Choi YS, Cho IH (2010) An effect of immediate dentin sealing on the shear bond strength of resin cement to porcelain restoration. $\mathrm{J}$ Adv Prosthodont 2:39-45

16. Duarte S Jr, de Freitas CR, Saad JR, Sadan A (2009) The effect of immediate dentin sealing on the marginal adaptation and bond strengths of total-etch and self-etch adhesives. J Prosthet Dent 102:1-9

17. Gresnigt MM, Cune MS, de Roos JG, Ozcan M (2016) Effect of immediate and delayed dentin sealing on the fracture strength, failure type and Weilbull characteristics of lithiumdisilicate laminate veneers. Dent Mater 32:e73-e81

18. Hashimoto M, Sano H, Yoshida E, Hori M, Kaga M, Oguchi H, Pashley DH (2004) Effects of multiple adhesive coatings on dentin bonding. Oper Dent 29:416-423

19. Hu J, Zhu Q (2010) Effect of immediate dentin sealing on preventive treatment for postcementation hypersensitivity. Int $\mathrm{J}$ Prosthodont 23:49-52

20. Jayasooriya PR, Pereira PN, Nikaido T, Tagami J (2003) Efficacy of a resin coating on bond strengths of resin cement to dentin. $J$ Esthet Restor Dent 15:105-113 discussion 113

21. Magne P, Kim TH, Cascione D, Donovan TE (2005) Immediate dentin sealing improves bond strength of indirect restorations. J Prosthet Dent 94:511-519

22. van den Breemer CRG, Ozcan M, Cune MS, van der Giezen R, Kerdijk W, Gresnigt MMM (2017) Effect of immediate dentine sealing on the fracture strength of lithium disilicate and multiphase resin composite inlay restorations. J Mech Behav Biomed Mater 72: 102-109

23. Kramer N, Reinelt C, Richter G, Frankenberger R (2009) Four-year clinical performance and marginal analysis of pressed glass ceramic inlays luted with ormocer restorative vs. conventional luting composite. J Dent 37:813-819

24. Jung H, Friedl KH, Hiller KA, Furch H, Bernhart S, Schmalz G (2006) Polymerization efficiency of different photocuring units through ceramic discs. Oper Dent 31:68-77

25. Goldberg J, Guth JF, Magne P (2016) Accelerated fatigue resistance of thick $\mathrm{CAD} / \mathrm{CAM}$ composite resin overlays bonded with light- and dual-polymerizing luting resins. J Adhes Dent 18:341348

26. Kameyama A, Bonroy K, Elsen C, Luhrs AK, Suyama Y, Peumans M, Van Meerbeek B, De Munck J (2015) Luting of CAD/CAM 
ceramic inlays: direct composite versus dual-cure luting cement. Biomed Mater Eng 25:279-288

27. Schulte AG, Vockler A, Reinhardt R (2005) Longevity of ceramic inlays and onlays luted with a solely light-curing composite resin. J Dent 33:433-442

28. Kramer N, Frankenberger R (2000) Leucite-reinforced glass ceramic inlays after six years: wear of luting composites. Oper Dent 25: 466-472

29. van Dijken JW (1999) All-ceramic restorations: classification and clinical evaluations. Compend Contin Educ Dent 20:1115-1124 1126 passim; quiz 1136

30. Kramer N, Frankenberger R (2005) Clinical performance of bonded leucite-reinforced glass ceramic inlays and onlays after eight years. Dent Mater 21:262-271

31. Gresnigt MMM, Ozcan M, Carvalho M, Lazari P, Cune MS, Razavi P, Magne P (2017) Effect of luting agent on the load to failure and accelerated-fatigue resistance of lithium disilicate laminate veneers. Dent Mater 33:1392-1401

32. Guess PC, Stappert CF, Strub JR (2006) Preliminary clinical results of a prospective study of IPS e.max Press- and Cerec ProCADpartial coverage crowns. Schweiz Monatsschr Zahnmed 116:493500

33. Chen SE, Park AC, Wang J, Knoernschild KL, Campbell S, Yang B (2019) Fracture resistance of various thickness e.max CAD lithium disilicate crowns cemented on different supporting substrates: an in vitro study. J Prosthodont

34. Longhini D, Rocha C, de Oliveira LT, Olenscki NG, Bonfante EA, Adabo GL (2019) Mechanical behavior of ceramic monolithic systems with different thicknesses. Oper Dent 44:E244-E253

35. Maeder M, Pasic P, Ender A, Ozcan M, Benic GI, Ioannidis A (2019) Load-bearing capacities of ultra-thin occlusal veneers bonded to dentin. J Mech Behav Biomed Mater 95:165-171

36. Guess PC, Selz CF, Steinhart YN, Stampf S, Strub JR (2013) Prospective clinical split-mouth study of pressed and CAD/CAM all-ceramic partial-coverage restorations: 7-year results. Int $\mathrm{J}$ Prosthodont 26:21-25

37. Naeselius K, Arnelund CF, Molin MK (2008) Clinical evaluation of all-ceramic onlays: a 4-year retrospective study. Int J Prosthodont 21:40-44

38. Barghi N, Berry TG (2002) Clinical evaluation of etched porcelain onlays: a 4-year report. Compend Contin Educ Dent 23:657-660 662, 664 passim; quiz 674

39. Peumans M, Voet M, De Munck J, Van Landuyt K, Van Ende A, Van Meerbeek B (2013) Four-year clinical evaluation of a selfadhesive luting agent for ceramic inlays. Clin Oral Investig 17: 739-750

40. Sailer I, Makarov NA, Thoma DS, Zwahlen M, Pjetursson BE (2015) All-ceramic or metal-ceramic tooth-supported fixed dental prostheses (FDPs)? A systematic review of the survival and complication rates. Part I: single crowns (SCs). Dent Mater 31:603-623

41. Sjogren G, Molin M, van Dijken JW (2004) A 10-year prospective evaluation of CAD/CAM-manufactured (Cerec) ceramic inlays cemented with a chemically cured or dual-cured resin composite. Int J Prosthodont 17:241-246

42. Valenti M, Valenti A (2009) Retrospective survival analysis of 261 lithium disilicate crowns in a private general practice. Quintessence Int 40:573-579
43. Fabbri G, Zarone F, Dellificorelli G, Cannistraro G, De Lorenzi M, Mosca A, Sorrentino R (2014) Clinical evaluation of 860 anterior and posterior lithium disilicate restorations: retrospective study with a mean follow-up of 3 years and a maximum observational period of 6 years. Int J Periodontics Restorative Dent 34:165-177

44. Felden A, Schmalz G, Federlin M, Hiller KA (1998) Retrospective clinical investigation and survival analysis on ceramic inlays and partial ceramic crowns: results up to 7 years. Clin Oral Investig 2: $161-167$

45. Guess PC, Strub JR, Steinhart N, Wolkewitz M, Stappert CF (2009) All-ceramic partial coverage restorations-midterm results of a 5year prospective clinical splitmouth study. J Dent 37:627-637

46. ElAyouti A, Serry MI, Geis-Gerstorfer J, Lost C (2011) Influence of cusp coverage on the fracture resistance of premolars with endodontic access cavities. Int Endod J 44:543-549

47. Stappert CF, Att W, Gerds T, Strub JR (2006) Fracture resistance of different partial-coverage ceramic molar restorations: an in vitro investigation. J Am Dent Assoc 137:514-522

48. Drummond JL, King TJ, Bapna MS, Koperski RD (2000) Mechanical property evaluation of pressable restorative ceramics. Dent Mater 16:226-233

49. Dietschi D, Magne P, Holz J (1993) An in vitro study of parameters related to marginal and internal seal of bonded restorations. Quintessence Int 24:281-291

50. Hickel R, Roulet JF, Bayne S, Heintze SD, Mjor IA, Peters M, Rousson V, Randall R, Schmalz G, Tyas M, Vanherle G (2007) Recommendations for conducting controlled clinical studies of dental restorative materials. Science committee project 2/98-FDI world dental federation study design (part I) and criteria for evaluation (part II) of direct and indirect restorations including onlays and partial crowns. J Adhes Dent 9(Suppl 1):121-147

51. Cheung GS, Lai SC, Ng RP (2005) Fate of vital pulps beneath a metal-ceramic crown or a bridge retainer. Int Endod J 38:521-530

52. Edelhoff D, Sorensen JA (2002) Tooth structure removal associated with various preparation designs for posterior teeth. Int $\mathrm{J}$ Periodontics Restorative Dent 22:241-249

53. Langeland K, Langeland LK (1970) Pulp reactions to cavity and crown preparation. Aust Dent J 15:261-276

54. van den Breemer C, Gresnigt M, Ozcan M, Kerdijk W, Cune MS (2019) Prospective randomized clinical trial on the survival of lithium disilicate posterior partial crowns bonded using immediate or delayed dentin sealing: short-term results on tooth sensitivity and patient satisfaction. Oper Dent 44:E212-E222

55. Frankenberger R, Reinelt C, Petschelt A, Kramer N (2009) Operator vs. material influence on clinical outcome of bonded ceramic inlays. Dent Mater 25:960-968

56. Moncada G, Silva F, Angel P, Oliveira OB Jr, Fresno MC, Cisternas P, Fernandez E, Estay J, Martin J (2014) Evaluation of dental restorations: a comparative study between clinical and digital photographic assessments. Oper Dent 39:E45-E56

Publisher's note Springer Nature remains neutral with regard to jurisdictional claims in published maps and institutional affiliations. 